Int. J. Electrochem. Sci., 15 (2020) 10722 - 10730

Short Communication

\title{
Influence of AC Interference on the Corrosion Behavior of 2507 Super Duplex Stainless in Simulated Concrete Pore Solution
}

\author{
Min Zhu, , Baozhu Zhao ${ }^{1}$, Li Liu $^{2}$, Yongfeng Yuan ${ }^{1}$, Shaoyi Guo ${ }^{1}$ \\ ${ }^{1}$ School of Mechanical Engineering \& Automation, Zhejiang Sci-Tech University, Hangzhou 310018, \\ China, \\ ${ }^{2}$ Interplex Electronic (HZ) Co., Ltd, Hangzhou 310018, China \\ *E-mail: zmii666@126.com
}

doi: $10.20964 / 2020.11 .69$

Received: 27 July 2020 / Accepted: 11 September 2020 / Published: 30 September 2020

\begin{abstract}
The corrosion behavior of 2507 super duplex stainless steel (SDSS) interfered by AC in simulated concrete pore solution containing $\mathrm{Cl}^{-}$was studied in this work. The results show that a rapid increase in $\mathrm{i}_{\mathrm{p}}$ and an apparent drop in $\mathrm{E}_{\mathrm{p}}$ as well the significant decrease in $\mathrm{R}_{\mathrm{f}}$ and $\mathrm{R}_{\mathrm{ct}}$ values suggest that the addition of $\mathrm{Cl}^{-}$and applied AC result in an obviously harmful effect on the passive film, and enhance the dissolution rate of film. The change in $N_{\mathrm{D}}$ and $N_{\mathrm{A}}$ values indicates that the presence of $\mathrm{Cl}^{-}$or AC application reduce the compactness of film, increase the amount of defects, and weaken the protective ability. Especially at the combined action of $\mathrm{Cl}^{-}$and imposed $\mathrm{AC}$, the instability of passive film becomes much worse, causing a further decrease in the anti-corrosion resistance of SDSS. AC facilitates the adsorption of $\mathrm{Cl}^{-}$and $\mathrm{H}^{+}$ions on the defects within passive film.
\end{abstract}

Keywords: Corrosion behavior; Imposed AC; Protective ability; Passive film

\section{$\underline{\text { FULL TEXT }}$}

(C) 2020 The Authors. Published by ESG (www.electrochemsci.org). This article is an open access article distributed under the terms and conditions of the Creative Commons Attribution license (http://creativecommons.org/licenses/by/4.0/). 